\title{
Cleft anterior segment with maternal hypervitaminosis $\mathrm{A}$
}

\author{
K Evans, M U Hickey-Dwyer
}

\begin{abstract}
We report a case of an 'hourglass' cornea and iris with reduplicated lens in the left eye of an infant girl. An excess of vitamin A products had been taken by the mother during pregnancy. Mechanisms by which vitamin A excess could have caused this are discussed.
\end{abstract}

Vitamin A and its analogues have become readily available on the market. High doses have been used to treat deficiency states, acne, other dermatoses and also in combination with other vitamins in 'healthy diet' regimens. ${ }^{1}$ In recent years many reports have appeared of birth defects in the children of users. ${ }^{2}$ The present report is of an unusual congenital abnormality thought to be due to excess intake by the mother of vitamin $A$ from a number of sources.

\section{Case report}

A Caucasian girl born to a healthy 26-year-old mother and an unrelated 32-year-old father came to the Ophthalmology Department with a history of an 'enlarged left eye' since birth. Examination under general anaesthesia revealed a cornea and iris with an hour-glass shape as if partially cleaved in two. At the hour-glass junction peripheral anterior synechiae were found. The cornea measured $14.5 \mathrm{~mm}$ horizontally, a maximum of $10.5 \mathrm{~mm}$ veritcally (Fig 1 ). Intraocular pressure was normal. Double or reduplicated clear lenses were seen behind the iris lying in a horizontal plane. No fundal abnormality was found. The right eye appeared normal. General physical examination showed no abnormalities or dysmorphic features. Laboratory investigations including a full blood count; tests for blood urea and electrolytes and random glucose gave normal results. Tests for

University of Liverpool Children's Unit, Alder Hey Hospital, Ophthalmology Department, Eaton Road, West Derby L12 2AP K Evans K Evans
M U Hickey-Dwye Correspondence to: Mr K Evans FRCS

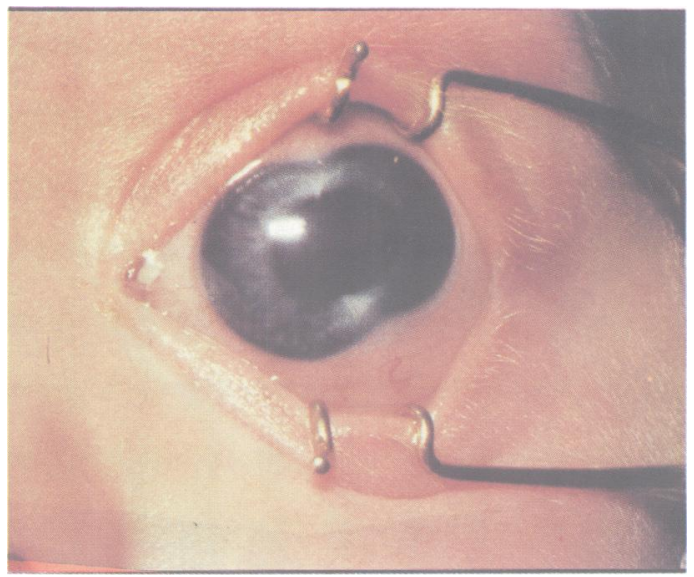

Figure 1 Close-up of left eye, illustrating bifid cornea and iris. syphilis, Toxocara and viral serology for cytomegalovirus, herpes, and rubella gave negative findings. The peripheral blood karyotype was a normal $46 \mathrm{XX}$. Computed tomography of the brain and orbits showed the abnormal cornea and double lens but no intracranial abnormality (Fig 2).

There was no family history of eye disorders. A full history from the mother disclosed no past medical problems. During pregnancy cervical carcinoma in situ was diagnosed, which was not treated until after delivery of the infant. The pregnancy was otherwise uneventful. There were no symptoms during pregnancy suggestive of hypervitaminosis $\mathrm{A}$. She had taken on average 10 capsules of royal jelly and six multivitamin tablets per week throughout the pregnancy. In addition she had consumed on average three meals containing liver per week during the first trimester only, which she had been informed would be beneficial.

\section{Discussion}

Reduplication of the lens is very rare ${ }^{34}$ Hourglass cornea and iris with reduplicated lens giving the appearance of a cleft splitting the anterior segment into two halves has not previously been reported. Apart from unusual features of the diet, extensive investigation failed to find a possible cause. Royal jelly contains proteins, water, carbohydrates, trace elements, and vitamins B, C, and E. So far there have been no reports of congenital eye anomalies associated with maternal ingestion of royal jelly, or with

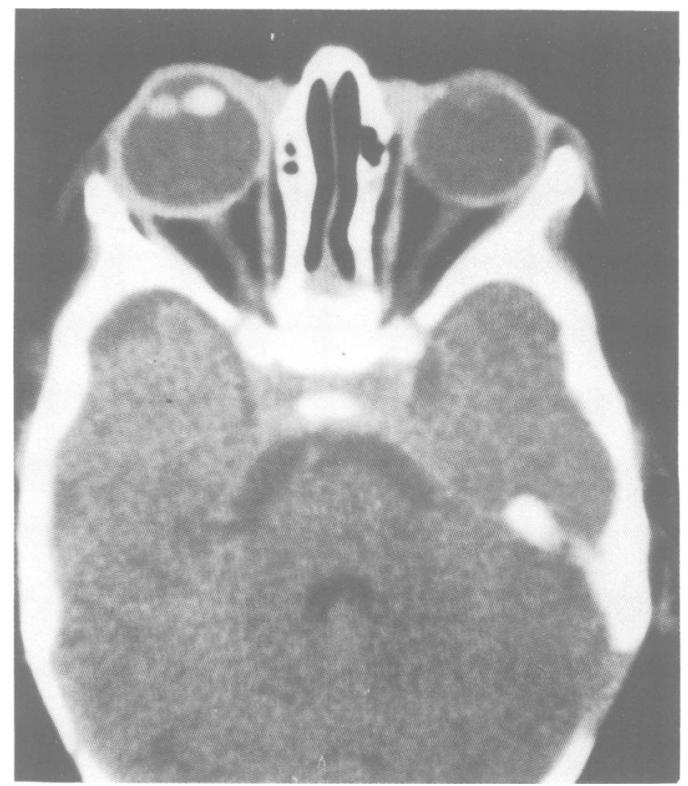

Figure 2 CT scan illustrating abnormal cornea and reduplicated lenses. 
cervical carcinoma in situ. Vitamin A, however, has been linked to many different teratogenic effects abroad, but not in Great Britain. ${ }^{5}$

Recent DHSS advice suggests that the dietary intake of vitamin A in pregnancy should not exceed 10000 IU daily; teratogenic effects have been reported at doses as low as $20000 \mathrm{IU}$ per day. Proprietary multivitamin tablets may contain 7500 IU each. A significant source of vitamin $\mathrm{A}$ in food is liver. A normal $100 \mathrm{~g}$ portion may contain 12-20 times the recommended daily dose. A normal diet (without liver or supplements) will contain about $2500 \mathrm{IU} .{ }^{6}$ We estimated that this mother took on average a daily dose of $25000 \mathrm{IU}$ in the first trimester.

Consent for blood vitamin A levels was not given, but the mother gave a clear history. Moreover, the history of vitamin and liver supplements was not asked about directly but volunteered when she was asked if she had an unusual diet during pregnancy. Therefore there is good circumstantial evidence that the fetus was exposed to high levels of vitamin A during the first trimester and that this was the cause of the resultant anomalies.

Affected infants have one or more features of a so called 'retinoid syndrome': ear defects, cleft lip and palate, craniofacial dysmorphism, cardio-aortic defects, thymic hypoplasia, hydrocephaly, and spina bifida. Ocular features include microphthalmia, anophthalmia, Goldenhar's syndrome, ${ }^{5}$ and retinal and optic nerve anomalies.'

Past cases of lens reduplication have been associated with facial anomalies and syphilis. ${ }^{3}$ It was assumed in at least one case that abnormal corneal tissue had interfered with lens vesicle migration from the surface ectoderm, splitting it in two. ${ }^{+}$It is known that excess vitamin A interferes with neural crest development. ${ }^{r}$ Possibly in this case abnormal corneal development (known to involve neural crest cells ${ }^{7}$ ) interfered in a similar way with lens vesicle migration and development.

We are grateful to Mr D B Clements and Mr D Leighton for permission to report on their patient.

1 Lammer EJ, Chen DT, Hoar RM, Agnish ND, Benke PJ Braun JT, et al. Retinoic Acid embryopathy. $N E n g l \mathcal{F} M e d$ 1985; 313: 837-41

2 Teratology Society Position Paper. Vitamin A during pregnancy. Recommendations for vitamin A use during pregnancy. Teratology 1987; 35: 269-75.

3 Lyford JH, Roy FH. Arhinencephaly unilateralis, uvea coloboma and lens reduplication. Am 7 Ophthalmol 1974; 77 315-8.

4 Richardson A. A case of reduplicated intraocular lens. Trans Can Ophthalmol Soc 1951; 14: 102-4.

5 Bielsalski HK. Comparative assessment of the toxicology of vitamin A and retinoids in man. Toxicology 1989; 57: 117-61. vitamin A and retinoids in man. Toxicology 1989; 57: 117-61. Department of Health and Social Security.
CMO(90)11/PL/CNO(90)10 London 1990.

7 Johnston MC, Noden DM, Hazelton RD. Origins of avian ocular and periocular tissue. Exp Eye Res 1979; 29: 27-43. 